\title{
PEMANFAATAN JENIS ROTAN OLEH MASYARAKAT DUSUN MUNGGUK MERANANG KECAMATAN SUNGAI LAUR KABUPATEN KETEPANG
}

\author{
(Ratan Utilization by Local People of Mungguk Meranang Village Sungai Laur District, \\ Ketapang Regency)
}

\author{
Sarikun, Iskandar, Gusti Hardiansyah \\ Fakultas Kehutanan Universitas Tanjungpura Jl. Daya Nasional, Pontianak 78124 \\ E-mail : ikunlaur.21@gmail.com
}

\begin{abstract}
Forest is a source of germplasm that has the potential to meet a variety of human needs such as: food, shelter, medicines and handicrafts. This species of rattan plant is one of the non wood forest products utilized by the people of Mungguk Meranang village and the species of rattan that are widely used as matting, rigging, and as vegetables. The purpose of this study was to determine the type of rattan, the species of activity made from rattan and the income of the rattan craftsmen comercial in Mungguk Meranang villaget, Sungai Laur District, Ketapang Regency. The results of the study carried out there are 10 types of rattan plants that are utilized, 12 types of woven made from rattan and net income of the community of Rp. 1,322,866 / year with a maximum net income of Rp. 2,268,000 / year and minimum net income of Rp. 276,000 / year.
\end{abstract}

Keywords: Korthalsia, Calamus and Daemonorops.

\section{PENDAHULUAN}

Hutan merupakan sumber plasma nutfah yang memilik potensi untuk memenuhi berbagai kebutuhan manusia seperti papan, pangan hingga obatobatan. Saat ini hampir semua manusia tergantung pada hutan, baik untuk mengambil manfaatnya secara langsung maupun tidak langsung. Salah satu manfaat yang diambil secara langsung dari hutan adalah hasil hutan non-kayu (Jumiati $d k k ., 2012$ ).

Kelompok hasil hutan yang disebut hasil hutan bukan kayu (HHBK) mencakup berbagai jenis sumber daya hutan, yang dimanfaatkan untuk berbagai kepentingan rumah tangga maupun perdagangan. Manfaat hasil hutan bukan kayu diantaranya sebagai sumber makanan, rempah-rempah, resin, obat-obatan, pengawet makanan, dan berbagai bentuk kerajinan sebagai penunjang kehidupan masyarakat. Manfaat hasil hutan bukan kayu yang banyak dimanfaatkan yaitu jenis rotan (Beer, 2005).

Utami $d k k$ (2017), rotan adalah satu sumber kekayaan hayati di Indonesia dan merupakan hasil hutan non-kayu yang sangat berpotensi. Januminro (2000), tanaman rotan memiliki berbagai keunikan, antara lain panjang batang dapat mencapai \pm 100 meter walupun diameternya hanya sebesar ibu jari tangan dan ibu jari kaki. Batang rotan memilik kelenturan dan kekuatan luar biasa, oleh karena itu batang rotan dapat dibuat menjadi berbagai macam bentuk perabotan rumah tangga, hiasanhiasan, dan alat pendukung sehari-hari. 
Pemanfaatan jenis rotan di Dusun Munggu Meranang ini merupakan pekerjaan yang sangat penting. Sebagian besar penduduknya merupakan petani oleh karena itu produk yang dibuat sesuai kebutuhan para petani yang fungsinya tidak mengalami perubahan dari dulu samapai sekarang. Sebagian besar masyarakatnya banyak menggunakan alat tradisional yang berasal dari anyaman jenis rotan, pemanfaatan jenis rotan merupakan pengetahuan turun temurun dari nenek moyang mereka yang disampaikan secara lisan dari generasi kegenarasi. Tujuan yang ingin dicapai dalam penelitian ini antara lain, mengidentifikasi jenis rotan yang dimanfaatkan masyarakat mengetahui bentuk pemanfaatan dan mendiskripsikan jenis anyaman yang dihasilkan dari tumbuhan rotan oleh masyarakat. Berapa pendapat masyarakat pengerajin tumbuhan rotan di Dusun Mungguk Meranang Kecamatan Sungai Laur Kabupaten Ketapang.

\section{METODE PENELITIAN}

Penelitian ini dilaksanakan di Dusun Mungguk Meranang Kecamatan Sungai Laur Kabupaten Ketapang. Penelitian dimulai pada tanggal 25 Febuari 2019 sampai pada tanggal 25 Maret 2019 dengan waktu yang dibutuhkan \pm 1 bulan di lapangan. Metode pengumpulan data dilakukan dengan cara survey lapangan, wawancara serta pengamatan langsung di lapangan. Pertimbangan penetapan responden adalah masyarakat pengerajin rotan.

Data yang dikumpulkan dalam penelitian meliputi data primer dan data sekunder. Data primer adalah data yang diperoleh langsung di lapangan melalui wawancara terhadap masyarakat di Dusun Mungguk Meranang yang menjadi responden dengan berdasarkan pertanayaan dalam kuisioner yang telah dipersiapkan sebelumnya. Data primer dalam penelitian yaitu jenis rotan, jenis kegiatan anyaman berbahan rotan dan pendapatan masyarakat pengerajin rotan. Data sekunder adalah data penunjang yang berhubungan dengan masalah penelitian yang diperoleh dari studi literatur dan sumber-sumber terkait dengan keadaan lokasi penelitian yang meliputi keadaan iklim, luas wilayah, komposisi penduduk, keadaan sosial ekonomi masyarakat, dan peta lokasi penelitian.

\section{HASIL DAN PEMBAHASAN}

\section{Jenis Rotan yang di Manfaatkan Dan Penyebarananya}

Tumbuhan rotan yang dimanfaatkan oleh masyarakat di Dusun Mungguk Meranang Kecamatan Sungai Laur Kabupaten Ketapang terdapat 10 jenis tumbuhan rotan yang terbagi atas 3 genus yaitu Korthalsia, Calamus dan Daemonorops. Genus Korthalsia yang terdiri atas rotan meiya, rotan udang semut, rotan dahan dan marau. Genus Calamus yang terdiri atas rotan taman, rotan sega, rotan irit, sedangkan dari genus Daemonorops yang terdiri dari rotan koroh, rotan getah dan rotan jernang. 
Tabel 1. Jenis Tumbuhan Rotan yang Dimanfaatkan oleh Masyarakat Dusun Mungguk Meranang (Species of Rattan that Utilized by Mungguk Meranang Village Communities)

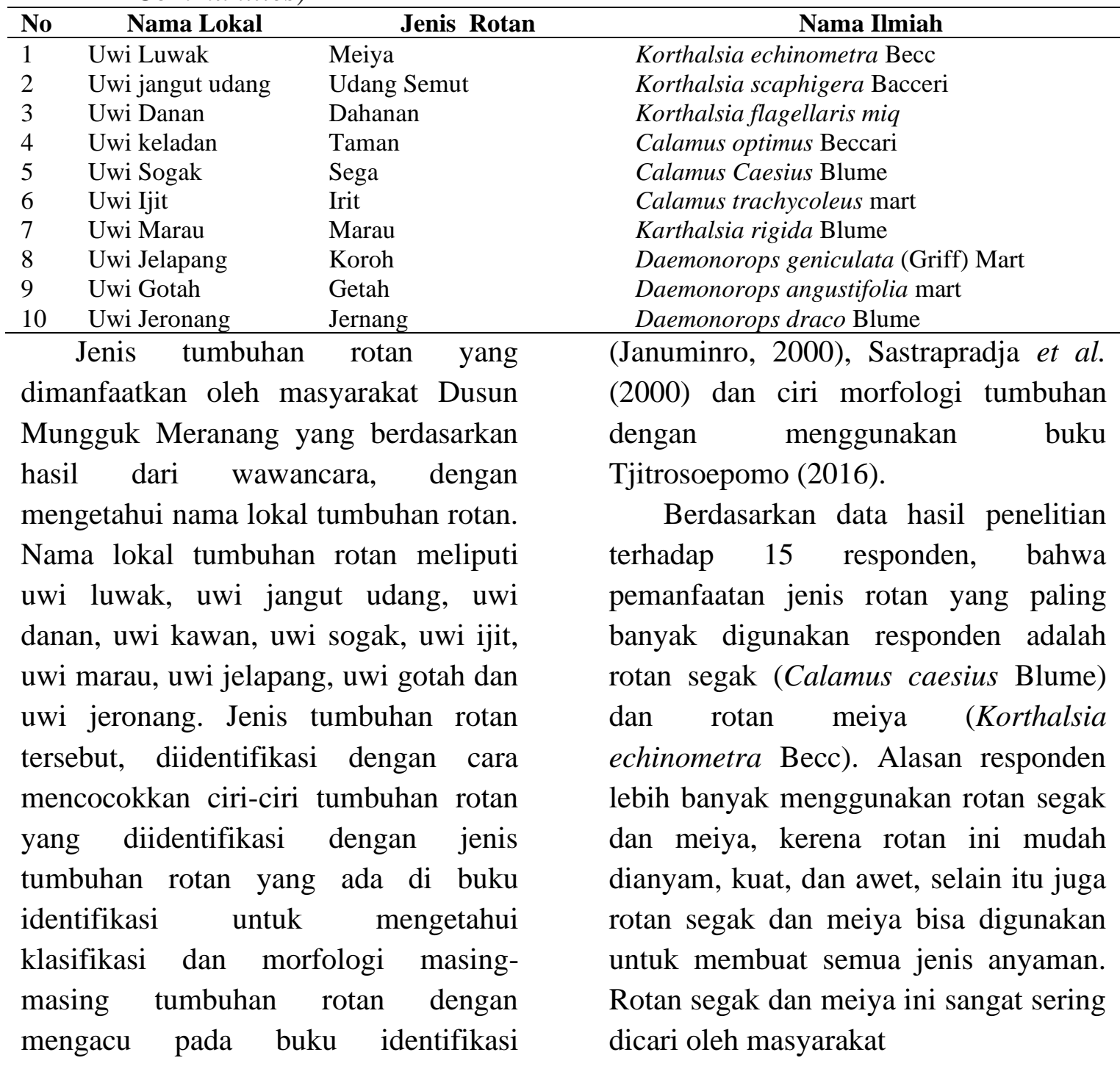

Klasifikasi jenis rotan :

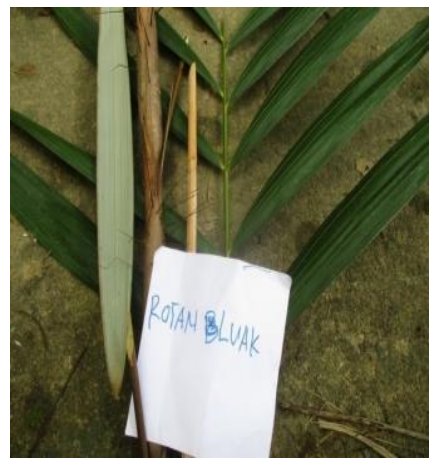

1. Rotan meiya

$\begin{array}{ll}\text { Kingdom } & \text { : Plantae } \\ \text { Sub Kingdom } & \text { Tracheobionta } \\ \text { Super Divisi } & \text { : Spermatophyta } \\ \text { Divisi } & \text { : Magnoliophyta } \\ \text { Kelas } & \text { : Liliopsida } \\ \text { Ordo } & \text { : Spacadiciflorae } \\ \text { Famili } & \text { : Palmae } \\ \text { Genus } & \text { : Korthalsia } \\ \text { Spesies } & \text { : Korthalsia echinometra Becc } \\ \text { Nama Lokal } & \text { : Uwi luwak }\end{array}$


JURNAL HUTAN LESTARI (2019)

Vol. 7 (4) : 1562 - 1570

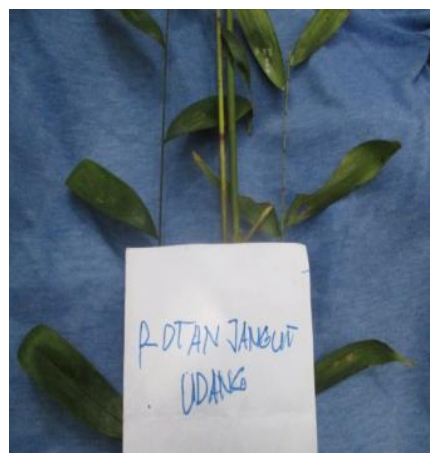

2. Rotan udang semut

Kingdom : Plantae

Sub Kingdom : Tracheobionta

Super Divisi : Spermatophyta

Divisi : Magnoliophyta

Kelas : Liliopsida

Ordo : : Spacadiciflorae

Famili : Palmae

Genus : : Korthalsia

Spesies : Korthalsia scaphigera Mart

Nama Lokal : Uwi jangut udang

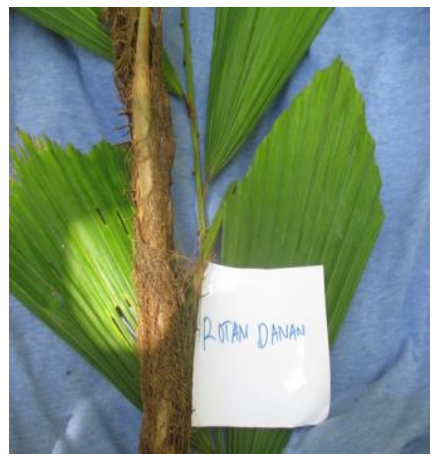

3. Rotan dahan

Kingdom : Plantae

Sub Kingdom : Tracheobionta

Super Divisi : Spermatophyta

Divisi : Magnoliophyta

Kelas : Liliopsida

Ordo : Spacadiciflorae

Famili : Palmae

Genus : : Korthalsia

Spesies : Korthalsia rigida Blume

Nama Lokal : Uwi danan

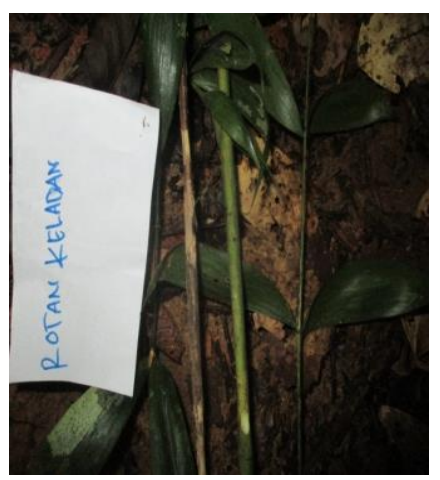

4. Rotan taman

Kingdom : Plantae

Sub Kingdom : Tracheobionta

Super Divisi : Spermatophyta

Divisi : Magnoliophyta

Kelas : Liliopsida

Ordo : : Spacadiciflorae

Famili : Palmae

Genus : Calamus

Spesies : Calamus optimus Beccari

Nama Lokal : Uwi keladan

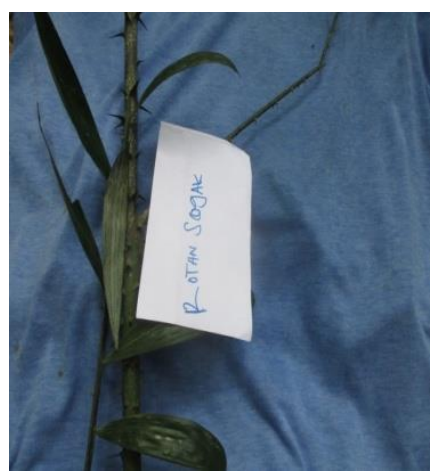

5. Rotan sega

Kingdom : Plantae

Sub Kingdom : Tracheobionta

Super Divisi : Spermatophyta

Divisi : Magnoliophyta

Kelas : Liliopsida

Ordo : Spacadiciflorae

Famili : Palmae

Genus : Calamus

Spesies : Calamus Caesius Blume

Nama Lokal : Uwi sogak 
JURNAL HUTAN LESTARI (2019)

Vol. 7 (4) : 1562 - 1570
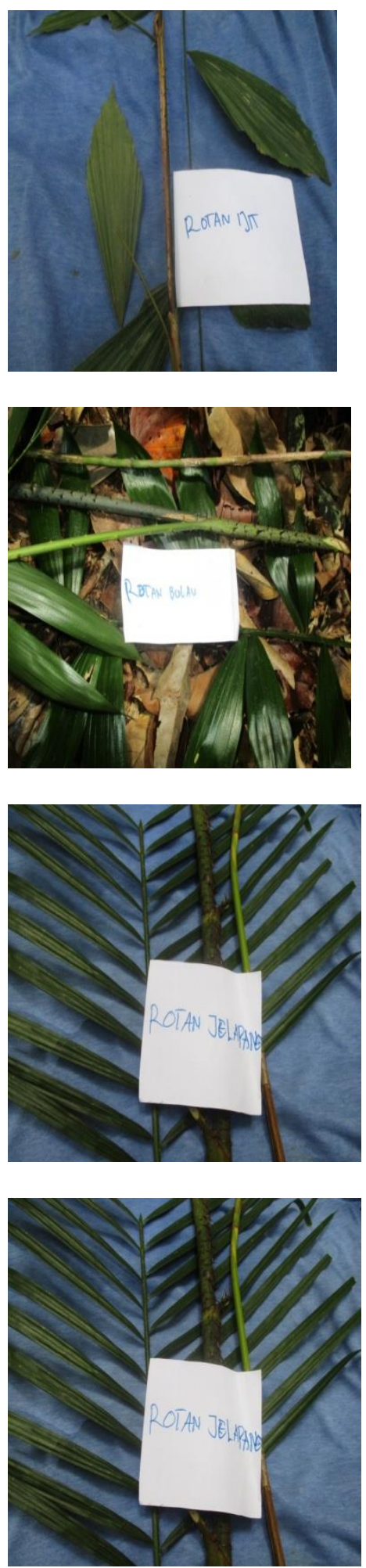

6. Rotan irit

Kingdom : Plantae

Sub Kingdom : Tracheobionta

Super Divisi : Spermatophyta

Divisi : Magnoliophyta

Kelas : Liliopsida

Ordo : : Spacadiciflorae

Famili : Palmae

Genus : Calamus

Spesies : Calamus trachycoleus Beccari

Nama Lokal : Uwi ijit

\section{Rotan lilin}

$\begin{array}{ll}\text { Kingdom } & \text { : Plantae } \\ \text { Sub Kingdom } & \text { Tracheobionta } \\ \text { Super Divisi } & \text { : Spermatophyta } \\ \text { Divisi } & \text { : Magnoliophyta } \\ \text { Kelas } & \text { : Liliopsida } \\ \text { Ordo } & \text { : Spacadiciflorae } \\ \text { Famili } & \text { : Palmae } \\ \text { Genus } & \text { : Calamus } \\ \text { Spesies } & \text { : Calamus javensis Blume } \\ \text { Nama Lokal } & \text { : Uwi bulau }\end{array}$

\section{Rotan koroh}

Kingdom : Plantae

Sub Kingdom : Tracheobionta

Super Divisi : Spermatophyta

Divisi : Magnoliophyta

Kelas : Liliopsida

Ordo : : Spacadiciflorae

Famili : Palmae

Genus : Daemonorops

Spesies : Daemonorops geniculata (Griff) Mart

Nama Lokal : Uwi jelapang

9. Rotan getah

Kingdom : Plantae

Sub Kingdom : Tracheobionta

Super Divisi : Spermatophyta

Divisi : Magnoliophyta

Kelas : Liliopsida

Ordo : Arecales

Famili : Arecaceae

Genus : Daemonorops

Spesies : : Daemonorops angustifolia mart

Nama Lokal : Uwi gotah 


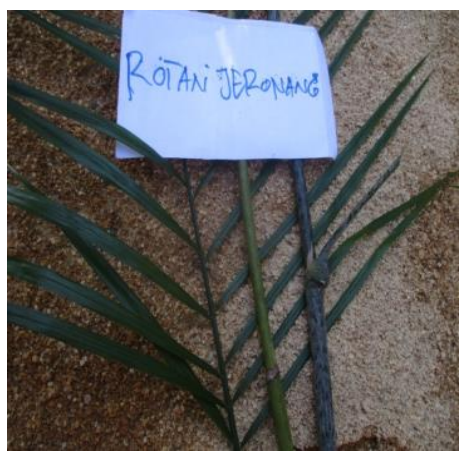

10.Rotan jernang

$\begin{array}{ll}\text { Kingdom } & \text { : Plantae } \\ \text { Sub Kingdom } & \text { Tracheobionta } \\ \text { Super Divisi } & \text { : Spermatophyta } \\ \text { Divisi } & \text { : Magnoliophyta } \\ \text { Kelas } & \text { : Liliopsida } \\ \text { Ordo } & \text { : Spacadiciflorae } \\ \text { Famili } & \text { : Palmae } \\ \text { Genus } & \text { : Daemonorops } \\ \text { Spesies } & \text { : Daemonorops drace Blume } \\ \text { Nama Lokal } & \text { : Uwi jeronang }\end{array}$

2. Jenis Anyaman yang Di hasilkan Dari Tumbuhan Rotan

Setiap jenis rotan yang ditemukan di Dusun Mungguk Meranang menghasilkan berbagai jenis anyaman yang berbeda jenis dan fungsinya.
Berdasarkan hasil penelitian tercatat sebanyak sekitar 12 jenis anyaman yang dihasilkan dari 10 jenis rotan yang ditemukan. Guna lebih jelasnya dapat dilihat pada tabel berikut ini:

Tabel 2. Bentuk Anyaman yang dihasilkan pada setiap jenis rotan (The form of woven produced on each species of rattan)

\begin{tabular}{lll}
\hline No & Jenis Rotan & Bentuk Anyaman \\
\hline 1 & Meiya & $\begin{array}{l}\text { Ronjong, Capan, Ragak, Bakul, Ayak Padi, Kampit, } \\
\text { Cempuduk,Nyiruk, Bajot. }\end{array}$ \\
2 & Udang Semut & Kursi, Tudung Saji, Meja, Ronjong, Ragak. \\
3 & Dahanan & Kursi, Meja, Bajot. \\
4 & Segak & Kursi, Tudung Saji, Meja, Ronjong, Capan, Ragak, Bakul, Ayak \\
& & Padi, Kampit, Cempuduk, Nyiruk, Bajot. \\
5 & Irit & Kursi, Tudung Saji, Meja. \\
6 & Marau & Kursi, meja, Cempuduk, Bajot. \\
7 & Korah & Kursi, Tudung Saji, Meja, Ronjong, Kampit. \\
8 & Getah & Tudung Saji, Ronjong, Ragak, Ayak Padi, Kampit. \\
9 & Taman & \\
\hline
\end{tabular}

Pemanfaatan tumbuhan khususnya rotan yang dilakukan di Dusun Mungguk meranang saat ini merupakan pengetahuan turun temurun dari nenek moyang mereka yang berasal dari interaksi mereka dengan alam sekitarnya. Umumnya pewaris pengetahuan tradisional dilakukan secara lisan dari generasi kegenerasi
(Soekarman dan Riswan, 1992). Saat ini bentuk kearifan tradisional yang masih ada di Dusun Mungguk Meranang khususnya pemanfaatan jenis rotan adalah pemanfaatan tumbuhan dengan disertai kesadaran untuk mejaga kelestarian spesies tumbuhan rotan yang digunakan. 


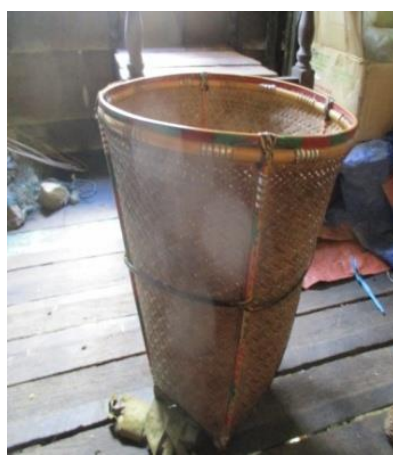

a

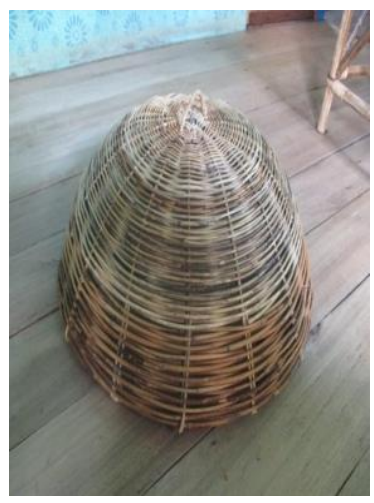

e

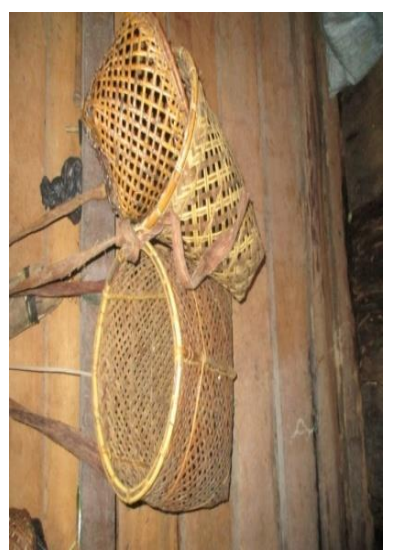

i

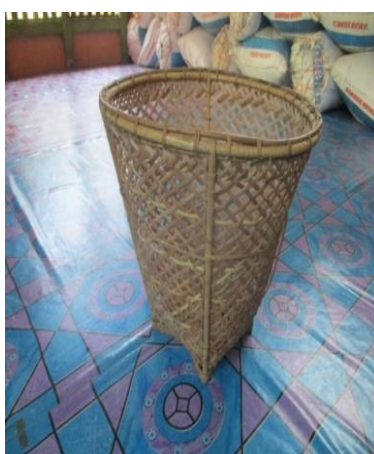

b

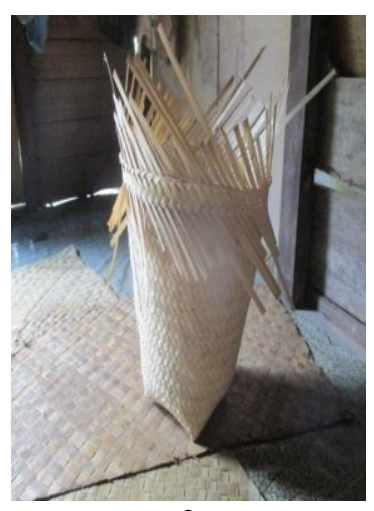

$\mathrm{f}$

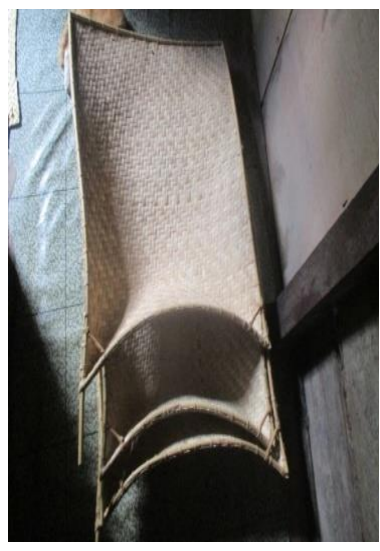

$\mathrm{j}$

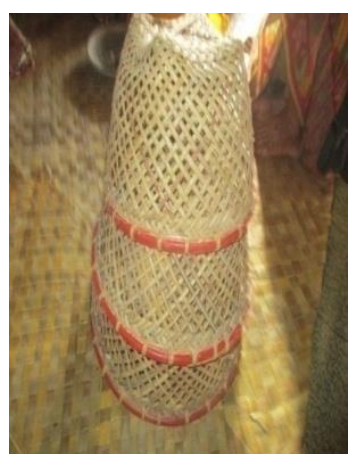

C

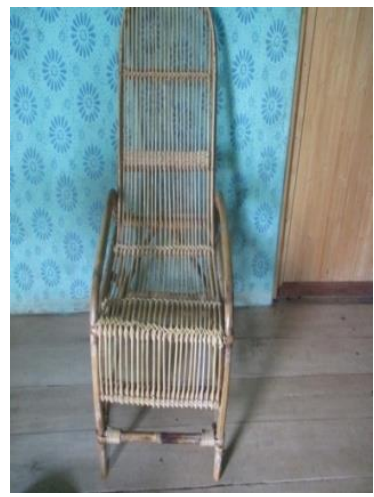

g

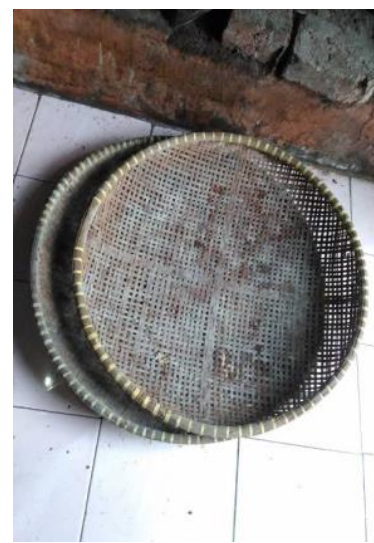

$\mathrm{k}$

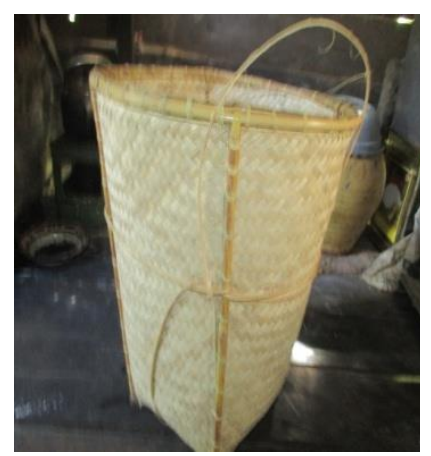

$\mathrm{d}$

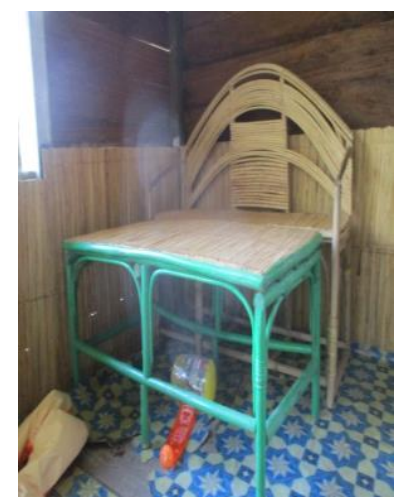

h

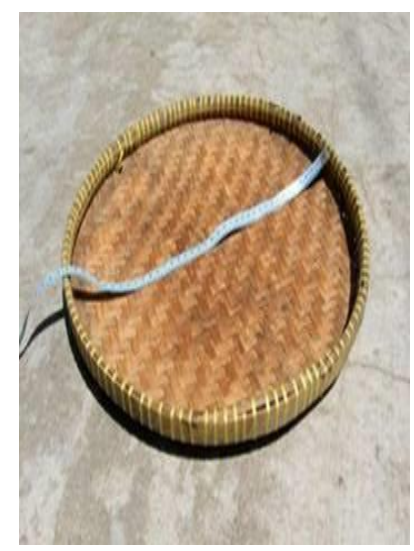

1

Gambar 2 . Bentuk Kerajinan dari Bahan Baku Jenis Rotan: a : Cempuduk; b: Ronjong; c :Ragak; d :Bajot; e : Tudung Saji; f : Bakul; g : Kursi; h : Meja; i : Kampit; $\mathrm{j}$ : Capan; $\mathrm{k}$ : Ayak Padi; 1 : Nyiruk (The form of handicraft made from raw materials of rattan type: a: Cempuduk; b: Oblong; c: Ragak; $d$ : Bajot; e: Saji's hood; f: Bakul; g: Chair; h: Table; i: Kampit; j: Capan; k: Paddy Sifter; l: Nyiruk)

3. Pendapatan Masyarakat yang rotan terdiri dari biaya peralatan, biaya

\section{Pengerajin Rotan}

Biaya produksi yang di keluarkan oleh masyarakat Dusun Mungguk Meranang dalam pemanfaatan tumbuhan akomendasi dan biaya tranportasi. Biaya peralatan sebesar Rp. 117.000/tahun dengan biaya akomendasi sebesar Rp. 214.000/tahun dengan 56\% dan biaya 
tranportasi sebesar Rp. 59.000 /tahun dengan $17 \%$ yang jumlah biaya produksi sebesar Rp. 343.080 /tahun.

Pendapatan bersih masyarakat dalam pemanfaatan tumbuhan rotan setelah penerimaan di kurangi biaya produksi. Penerimaan sebesar rata-rata Rp. 1.110.333 /tahun dan biaya produksi sebesar rata-rata Rp. 331.800 /tahun sehingga pendapatan bersih masyarakat sebesar rata-rata Rp. 1.322.866/tahun. Maxsimum penerimaan masyarakat sebesar Rp. 2.560.000 /tahun dan minimum penerimaan Rp. 570.000 /tahun, maxsimum biaya produksi masyarakat sebesar Rp. 436.000 /tahun dan minimum biaya produksi sebesar Rp. 259.000 /tahun serta maxsimum pendapatan bersih masyarakat sebesar Rp. 2.268.000/tahun dan minimum pendapatan bersih sebesar Rp. 276.000 /tahun.

\section{KESIMPULAN}

Berdasarkan hasil analisis yang telah dilakukan dapat disimpulkan bahwa:

1. Berdasarkan data yang diperoleh di lokasi penelitian tercatat 10 jenis rotan yang dimanfaatkan oleh masyarakat Dusun Mungguk Meranang.

2. Pemanfaatan dan pengolahan rotan untuk bahan kerajinan yang telah dilakukan oleh masyarakat Dusun Mungguk Meranang menghasilkan umumnya terdapat 12 jenis anyaman dengan berbagai bentuk dan fungsi yang khas.

3. Nilai ekonomi dari pemanfaatan tumbuhan rotan dengan pendapatan bersih masyarakat sebesar rata-rata Rp. 1.322.866/tahun dengan maxsimum pendapatan bersih sebesar
Rp. 2.268.000/tahun dan minimum pendapatan bersih sebesar Rp. $276.000 /$ tahun.

\section{SARAN}

Berdasarkan hasil analisis yang telah dilakukan dapat disimpulkan bahwa. Jenis rotan yang banyak digunakan diharapkan masyarakat Dusun mungguk meranang dapat melakukan pembudidayaan rotan agar keberadaan rotan tersebut tetap ada dan terus dimanfaatkan secara berkelanjutan, diharapkan masyarakat dapat lebih mengenal produk-produk kerajinan tangan tersebut kepada masyarakat di luar Dusun Mungguk Menranang bisa mengenal kerajinankerajinan anyaman yang ada supaya lebih memiliki nilai jual dan bisa membantu perekonomian masyarakat setempat. Perlu adanya peran serta dan inisiatif pemerintah daerah dan dinas yang terkait terhadap pelestarian kebudayaan khususnya kerajianan anyaman.

\section{UCAPAAN TERIMAKASIH}

Penelitian ini dengan terselesaikan atas bantuaan berbagai pihak. Saya mengucapkan terima kasih kepada Kepala Desa, Kepala Dusun dan para pengerajin, karena telah membantu saya dalam melakukan penelitian.

\section{DAFTAR PUSTAKA}

Beer, JD. 2005. Kekayaan Hutan Asia: Makanan, Rempah-rempah, kerajinan Tangan, dan Resin. Jakarta: PT Gramedia Pustaka Utama.

Janimonro. 2000. Rotan Indonesia, Potensi, Budi Daya, Pemungutan, Pengolahan, Standar Mutu, dan Prospek pengusahaan. Yogyakarta: Kanisius 
Jumiati, Hariyadi B, Murni P. 2012. Studi Etnobotani Rotan Sebagai Bahan Kerajinan Anyaman Pada Suku Anak Dalam (SAD) Di Dusun IIISenami, Desa Jebak Kabupaten Batanghari, Jambi.

Sastrapradja dan Setijati. 2000. Diantara alunan Bambu dan Bisikan Rotan. Bogor. Naturae Indonesia.

Soekarman, Riswan S. 1992. Status Pengetahuan Etnobotani Di Indonesia. Di dalam: Seminardan lokarya Nasional Etnonotani,
Cisarua Bogor: Depertemen

Pendidikan dan Kebudayaan RI, Hal 1-7.

Tjitrosoepomo G. 2016. Morfologi Tumbuhan. Yogyakarta: Gadjah Mada University Press.

Utami S, Wardenaar E, Idham M. 2017. Studi Pemanfaatan Rotan oleh Masyarakat Dusu Kebak Raya di Kawasan Hutan Desa Suruh Tembawang Kecamatan Entikong Kabupaten Sanggau. Jurnal Hutan Lestari 5(3):578-582. 